\title{
O NOVO CÓDIGO DE PROCESSO CIVIL E AS AÇÕES POSSESSÓRIAS - NOVAS PERSPECTIVAS PARA OS CONFLITOS FUNDIÁRIOS COLETIVOS?
}

\section{THE NEW CODE OF CIVIL PROCEDURE AND THE POSSESSORY ACTIONS - NEW PERSPECTIVES FOR THE COLLECTIVES LAND CONFLICTS?}

\author{
Cláudio Oliveira de Carvalho ${ }^{1}$ \\ Raoni Rodrigues ${ }^{2}$
}

\section{Resumo}

Em 18 de março de 2016, um novo Código de Processo Civil passará a viger no Brasil, trazendo diversas inovações normativas, dentre as quais se destacam algumas poucas modificações no procedimento das ações possessórias para conflitos fundiários coletivos. As instituições e movimentos sociais ligados à causa da Reforma Urbana, depois de grande mobilização durante o processo legislativo do novo Código, não conseguiram transformar em leis a maior parte de suas demandas, e vêm o aludido texto legal como fruto de uma vitória conservadora. Resta ao presente estudo analisar as suas principais modificações normativas, avaliando se elas serão realmente capazes de enfrentar o grave problema de habitação que marca a evolução histórica da maioria das cidades brasileiras. Objetiva-se, com isso, enriquecer o debate sobre a efetivação do direito à moradia, seja no âmbito local, seja no internacional, já que 2016 também é o ano da Habitat 3, a Terceira Conferência das Nações Unidas sobre Moradia e Desenvolvimento Urbano Sustentável.

Palavras-chave: Direito à Urbanístico; Direito à Moradia; conflitos fundiários urbanos; ações possessórias; novo Código de Processo Civil.

\begin{abstract}
On March 18, 2016, a new Civil Procedure Code will come into effect in Brazil, bringing several regulatory innovations, among which stand out a few changes in the procedure of possessory action to collective land conflicts. Institutions and social movements linked to the cause of Urban Reform, after massive mobilization during the legislative process of the new Code, failed to turn into laws most of their demands, and come the aforementioned legal text as the result of a conservative victory. It remains to this study to analyze its main legislative changes, assessing whether they will actually be able to address the serious housing problem which marks the historical evolution of most Brazilian cities. The objective is to thereby enrich the debate on the realization of the right to housing, either locally, or in the international since 2016 is also the year of Habitat 3, the Third United Nations Conference on Housing and Sustainable Urban Development. Keywords: Right to Urban; Right to housing; urban land conflicts; possessory actions; new Civil Procedure Code.
\end{abstract}

\footnotetext{
${ }^{1}$ Doutor em Desenvolvimento Regional e Urbano pela Universidade Salvador (2014). Professor assistente da Universidade Estadual do Sudoeste da Bahia. Integrante do Núcleo de Assessoria Jurídica Alternativa - NAJA. PROEX/UESB - Vitória da Conquista/Bahia. E-mail: ccarvalho@uesb.edu.br

2 Especialista em Direito Tributário pela Universidade Candido Mendes, Professor da Faculdade Batista Brasileira - FBB, Bahia. E-mail: raoniarodrigues@gmail.com
} 


\section{INTRODUÇÃO}

Ao longo do processo de formação e crescimento das cidades brasileiras, a legislação urbanística teve um importante papel de servir aos interesses de uma minoria hegemônica, atuando como instrumento de segregação ou exclusão social, e delimitando acessos distintos a elementos urbanos dos mais essenciais. Naturalmente, com o passar do tempo, os movimentos sociais e instituições ligados à causa da Reforma Urbana passaram a lutar por uma elaboração legislativa condizente com os anseios e necessidades da população urbana. O resultado disso foi significativo, já que resultou na criação de uma nova ordem jurídico urbanística, inaugurada com alguns capítulos da Constituição Federal de 1988 (CF/88), e mais tarde fortalecida com o advento do Estatuto da Cidade de 2001 (EC).

O progressismo que marcou a renovação da legislação urbanística nacional, por outro lado, não tem conseguido lidar com a premissa de que existe uma relação de antagonismo entre lei e realidade social (CASTRO, 2000, p. 79), um claro distanciamento entre teoria e prática. E a referida premissa não é exclusividade do Direito brasileiro. Em documento preliminar da Habitat 3, a conferência da Organização das Nações Unidas (ONU) sobre moradia e desenvolvimento urbano sustentável, existem evidências de que, independentemente do direito à moradia ser positivado constitucionalmente em praticamente todos os países do mundo, a insegurança jurídica na posse de imóveis urbanos ainda é uma realidade global. Anualmente, milhões de pessoas são expulsas de suas habitações contra a sua vontade, por meio de decisões judiciais facilmente contestáveis, e sem receberem as compensações devidas (ONU, 2015, p. 4).

Reconhecendo a necessidade de proteção jurídica da posse como elemento essencial à moradia adequada, a Habitat 3 se voltará, dentre outras coisas, para a criação de novas abordagens teóricas a respeito da posse (ONU, 2015, p. 9). Para isso, deverão ser discutidos os limites e as possibilidades dos mecanismos legais já existentes, além da possibilidade de desenvolvimento de instrumentos jurídicos que sejam mais efetivos. O aludido debate será deveras salutar para o Brasil, visto que 2016, ano da Habitat 3, é também o ano em que um novo Código de Processo Civil (CPC) entrará em vigor, depois de intenso debate sobre as mudanças nas regras das ações possessórias.

O Brasil é um dos países com o maior déficit habitacional do mundo. Mais de seis milhões de famílias não possuem moradia, o que corresponde a cerca de 22 milhões de pessoas vivendo às margens de um dos direitos humanos mais fundamentais (BOULOS, 2012, p. 14). Por outro lado, a 
concentração de renda e propriedade imóvel no Brasil exibem números semelhantes, mas opostos. O número de residências vazias é praticamente o mesmo que o correspondente ao déficit habitacional: 6,07 milhões (AMADO, 2015, p. 1). A ausência de uma política pública habitacional realmente resolutiva e a existência de uma variedade de imóveis urbanos carentes de função social $^{3}$ são motivos determinantes para a existência de conflitos fundiários urbanos. A ocupação desses imóveis por movimentos sociais acaba revelando para toda a sociedade um grave problema social que produz repercussões significativas na gestão da cidade e na vida de muitos de seus habitantes (BRASIL, 2013, p. 11).

Pelo exposto, o presente estudo buscará compreender o conteúdo jurídico emanado dos conflitos possessórios coletivos. Sabe-se que a ocupação de imóveis gera embates sociais que na maioria das vezes são judicializados por meio das ações possessórias ${ }^{4}$. Deste modo, espera-se avaliar se as modificações trazidas pelo novo CPC irão permitir uma segurança jurídica da posse mais sólida em favor das ocupações coletivas.

\section{O DIREITO À MORADIA E A SUA RELAÇÃO COM A POSSE}

O direito à moradia é reconhecido internacionalmente como um dos mais básicos para a sobrevivência e a dignificação dos seres humanos. A própria Declaração Universal dos Direitos Humanos de 1948, em seu artigo XXV, estabelece que: "Toda pessoa tem direito a um padrão de vida capaz de assegurar a si e a sua família saúde e bem-estar, alimentação, vestuário e habitação [...]" (ONU, 2015, p. 1). O Brasil, signatário dos principais documentos de direitos humano internacionais, internalizou em seu sistema jurídico esse direito fundamental, dispondo sobre ele na CF/88 e em uma série de leis esparsas ${ }^{5}$.

É necessário ressaltar que a ideia de moradia não se limita à mera busca por um teto, um abrigo. Principalmente depois do Pacto Internacional de Direitos Econômicos, Sociais e Culturais

\footnotetext{
3 Imóveis carentes de função social são aqueles mantidos vazios pelos proprietários, ou, mesmo que edificados, permanecem inutilizadas ou subutilizadas. O que determinará se um determinado imóvel cumpre o mínimo de requisitos para se considerar "socialmente funcional" são os dispositivos legais elaborados por cada Município, por meio do plano diretor.

${ }^{4}$ Cabe frisar que são três as ações ou interditos possessórios previstos na ordem jurídica brasileira: a ação de reintegração de posse, a de manutenção de posse e o interdito proibitório, cuja pretensão se direciona, respectivamente, para os casos de esbulho, turbação ou ameaça.

${ }^{5} \mathrm{~A} C F / 88$ coloca a moradia dentre os direitos sociais. O direito à moradia ainda é objeto do Estatuto da Cidade, da Lei no 11.124, que dispõe sobre o Sistema Nacional de Habitação de Interesse Social, além da Lei no 11.481, que dispõe sobre a Regularização Fundiária de Interesse Social em Imóveis da União.
} 
(PIDESC), de 1966, passou-se a defender a ideia de uma moradia adequada, que seria aquela dotada dos seguintes componentes:

1. Segurança jurídica da posse;

2. Disponibilidade dos serviços, materiais, benefícios e infraestrutura;

3. Gastos suportáveis;

4. Habitabilidade;

5. Acessibilidade;

6. Localização; e

7. Adequação cultural" (ONU, 2014, p. 2).

É visível que a segurança jurídica da posse é o primeiro e mais importante dos componentes, pois costuma dar ensejo a todos os outros.

A necessidade de proteção à posse é essencial principalmente em países como o Brasil, nos quais a ocupação para fins de moradia não é uma opção. Trata-se, na verdade, da única oportunidade que parcela considerável da população possui de ter acesso a uma habitação (BOULOS, 2012, p. 46), devido aos preços exorbitantes dos imóveis, motivados pelas práticas especulativas do Mercado, e à ausência de políticas habitacionais capazes de atender às demandas sociais das cidades contemporâneas. Entendendo a posse como fenômeno inerente do modelo capitalista de desenvolvimento urbano hoje vigente, a ONU, através do Comentário Geral no 4 do Comitê dos Direitos Econômicos, Sociais e Culturais (DESC), orienta que, seja qual for o tipo de ocupação, "[...] todas as pessoas devem possuir um grau de segurança de posse que lhes garanta a proteção legal contra despejo forçado, perturbação e qualquer tipo de outras ameaças" (ONU, 2014, p. 7).

É notável que a abordagem da ONU considera as ocupações e a proteção jurídica da posse como sendo partes integrantes do direito à moradia adequada, e como meios de efetivação para o mesmo. Com base nisso, surge a necessidade de rever o conteúdo do direito à moradia presente nos documentos legais, sobretudo na Constituição brasileira. Sabe-se que ainda hoje existe uma visão mais conservadora que tende a limitar o direito à moradia a uma condição de norma programática, ou seja, uma exigência a ser cobrada do Estado, assim como a saúde, a segurança pública e a educação. Não poderia ser invocado quando dois particulares se envolvessem em conflitos, e, portanto, não poderia ser oponível aos proprietários de imóveis 6 .

\footnotetext{
${ }^{6}$ Em estudo que avaliou os acórdãos proferidos por desembargadores do estado de São Paulo, Núbia Campos (2015) chegou à conclusão que muitos magistrados tendem a considerar o direito à moradia como
} 
Mas a doutrina jurídica contemporânea já superou a concepção mais limitada do direito à moradia, fazendo referência a um direito "de" moradia. Quando se modifica a locução destacada, o conteúdo desse direito se amplia. Passa a abarcar, por isso, não apenas a prestação de políticas habitacionais por parte do Estado, mas também a possibilidade de ser invocado durante conflitos possessórios entre particulares. Essas previsões não se encontram estruturadas em um conjunto específico de normas jurídicas, mas podem ser facilmente verificáveis como "consequência jurídica da proteção possessória, eventualmente dada ao possuidor de boa-fé, de um imóvel urbano para habitação" (CASTRO, 2000, p. 93).

A despeito das exigências constitucionais relativas ao cumprimento da função social da propriedade e à essencialidade do direito de moradia, as soluções judiciais aplicadas aos conflitos fundiários urbanos ainda costumam ignorar as particularidades públicas desses embates. As origens do litígio dificilmente são enfrentadas, o que acaba por gerar ainda mais passivos sociais e jurídicos, sobretudo nas cidades mais populosas (BRASIL, 2015, p. 11).

Ao promover o despejo forçado dos ocupantes, o judiciário tende a estimular o retorno à condição anterior ao conflito, que se caracteriza pela existência de inúmeros terrenos urbanos carentes de função social, rodeados por populações de sem teto que vêm em tais terrenos a única possibilidade de adquirir moradia. O despejo, por isso, costuma perpetuar a tensão existente entre as duas diferentes partes, e o conflito a qualquer momento retorna ao seio social.

Para reduzir a distância existente entre os processos judiciais e a concretização do direito à moradia, diversos movimentos sociais e instituições ligados à causa da Reforma Urbana procuraram levar ao Legislativo nacional orientações para mudanças nas regras processuais das ações possessórias ${ }^{7}$. Tendo em vista que na época um novo CPC estava sendo elaborado, as aludidas orientações foram incluídas no Projeto de Lei (PL) do novo Código, para que fosse devidamente votada ao longo do processo legislativo. Nesse interim, as forças conservadoras do Congresso Nacional conseguiram se articular para frear parte das demandas que viriam a ser

norma programática, que depende de efetivação infra legal. Ela demonstra que essa visão de conferir menor eficácia ao direito à moradia ainda é comum no judiciário brasileiro, apesar da doutrina costumar apontar para direção inversa.

${ }^{7}$ Cabe diferenciar direito material e direito processual. Enquanto o primeiro deles estipula direitos e deveres, o segundo trata das regras procedimentais que serão seguidas em uma ação judicial para a realização dos direitos ou o cumprimento dos deveres, e geralmente são organizados em um código processual, como é o caso do próprio CPC. Sem regras processuais que os garantam, os direitos materiais dificilmente alcançam sua efetividade jurídica. Vê-se que os movimentos envolvidos com a luta pela democratização da moradia claramente modificaram suas estratégias legislativas. Deixaram de exigir que o direito à moradia seja repetido em inúmeros documentos legais, e passaram a exigir modificações nas regras processuais garantidoras de um processo judicial capaz de concretizar o aludido direito. 
absorvida pelo novo CPC, algo que, como será verificado nos próximos tópicos, acabou por limitar o caráter social das ações possessórias vigentes a partir de 18 de março de 2016.

\section{OS CONFLITOS FUNDIÁRIOS URBANOS}

Os conflitos fundiários urbanos são inerentes ao modelo capitalista de produção das cidades. A concentração de propriedade e a especulação imobiliária, somadas à ineficiência das políticas públicas habitacionais, acabam por gerar dois grupos sociais distintos que frequentemente irão colidir seus interesses: (a) de um lado os proprietários de grandes glebas urbanas, que se comportam como detentores de um direito de propriedade absoluto, que thes permite ter bens imóveis sem thes proporcionar qualquer função social; e (b) no extremo oposto se encontram os grupos de segregados do processo de urbanização, cuja ocupação de imóveis vazios ou inutilizados é a única forma de eles possuírem, pelo menos por algumas noites, um teto sobre suas cabeças.

Segundo o artigo 3o da Resolução no 87, emitida pelo Ministério das Cidades (BRASIL, 2013, p. 19), o conflito fundiário urbano é definido como a:

Disputa pela posse ou propriedade de imóvel urbano, bem como impacto de empreendimentos públicos e privados, envolvendo famílias de baixa renda ou grupos sociais vulneráveis que necessitem ou demandem a proteção do Estado na garantia do direito humano à moradia e à cidade.

E, adentrando no objeto análise do presente artigo, o que dizer das ações possessórias iniciadas contra a ocupação de imóveis não dotados de sua função social? Na complexidade das relações sociais do mundo contemporâneo, é natural que, em alguns casos, dois ou mais sujeitos tenham direitos distintos sobre um mesmo objeto. Quando os limites de exercício desses direitos não estão bem estabelecidos, o conflito surge naturalmente (CASTRO, 2000, p. 89). No caso das ações possessórias analisadas, vê-se, recorrentemente, o embate entre dois direitos distintos: a propriedade versus o direito de moradia consubstanciada na posse temporária de um imóvel ${ }^{8}$. Mas, analisando a questão criticamente, esse conflito não é decorrente da técnica jurídica, mas de questões políticas e culturais. Não se pode dizer que existem direitos colidindo. O que ocorre é o choque entre um direito e um privilégio:

1. O acesso à moradia por parte de grupos sociais vulneráveis, e

\footnotetext{
${ }^{8}$ Para a maioria dos juristas a posse não seria um direito em si, mas um fato social que gera repercussões no mundo jurídico. Um breve exemplo: não existe um direito à posse de um edifício vazio, mas um direito à moradia. A manutenção na posse depende do exercício de habitá-la, sob pena desse fato não ser digno de defesa jurídica.
}

Revista de Direito da Cidade, vol. 07, no 4. Número Especial. ISSN 2317-7721 pp.1750-1770 1755 
2. Privilégio de uma minoria que acumula propriedades imóveis urbanas sem Ihes dar qualquer função social.

Diante da disparidade existente entre os interesses em questão, a ação possessória utilizada por um proprietário de imóvel sem função social contra uma coletividade não poderia ter as mesmas regras processuais de conflitos individuais. A ocupação, como exercício legítimo de posse, é de fundamental interesse público, como veremos a seguir, e precisa ser protegida através de meios processuais eficazes.

\section{A QUESTÃo dA ILEGITIMIDAdE DA POSSE PROVENIENTE DAS OCUPAÇÕES COLETIVAS}

A posse proveniente das ocupações coletivas sofre de limitações jurídicas no que se refere a sua legitimidade, que precisam ser devidamente enfrentadas para o bom seguimento do presente estudo. O Direito brasileiro considera que a posse oriunda de ocupações realizadas sem o consentimento do proprietário é injusta. Como regra adicional do sistema jurídico, a posse injusta não pode se converter para justa, o que impediria a defesa possessória dos ocupantes. Deste modo, ao ver seu imóvel ser ocupado contra a sua vontade, o proprietário facilmente pode se valer de uma ação possessória alegando que o grupo de pessoas que adentraram em seu bem o fizeram de forma ilegal. Não resta qualquer dúvida quanto a isso.

O problema de aplicação normativa se encontra quando existe irregularidade também por parte do proprietário. Sabe-se que irregularidade fundiária não é uma exclusividade dos grupos de baixa renda. As classes mais abastadas também são violadoras das legislações fundiárias, mas, diferentemente da população mais pobre e carente de alternativas, elas fazem por opção (BRASIL, 2010, p. 12).

É justamente quando a posse irregular dos ocupantes confronta o exercício irregular do direito à propriedade que a defesa possessória deve assumir bases jurídicas mais amplas. No caso das ocupações de imóveis carentes de função social, a manutenção dos ocupantes nos imóveis acaba se tornando mais legítima do que o despejo que acarretará um retorno do bem a um estado de subaproveitamento.

É claro que esse entendimento necessita de uma exegese mais ampla, que considere as ações possessórias dentro de um sistema jurídico constitucionalizado, que deve prezar pela harmonização das diferentes regras e princípios que convivem no sistema. Uma interpretação mais ampla é a forma mais justa e eficaz de resolver conflitos jurídicos como o analisado no momento.

Revista de Direito da Cidade, vol. 07, no 4. Número Especial. ISSN 2317-7721 pp.1750-1770 1756 
Quando os conflitos possessórios envolvem um choque entre o uma posse ilegítima e uma propriedade exercida de forma irregular, o direito à moradia e a função social da propriedade devem ser invocados para produzir decisões judiciais condizentes com o ordenamento constitucional brasileiro.

Outra questão a ser enfrentada é se a posse oriunda de uma ocupação coletiva pode assumir o estado de realizador de um direito à moradia não concretizado por políticas públicas. Existem instrumentos jurídicos próprios para a regularização fundiária, como a Regularização Fundiária de Interesse Específico, prevista na Lei no 11.977 de 2009, que seria um instrumento mais apropriado para a superação dessa problemática. Por outro lado, o artigo 8o do Estatuto da Cidade traz o instituto da desapropriação sanção, capaz de absorver os imóveis que não possuem sua função social. Trata-se de uma forma mais direta e apropriada de limitar o direito de propriedade quando mal exercido.

Ocorre que em um país no qual as políticas públicas e as ações estatais raramente procuram reverter o quadro de segregação socioespacial presente nas suas cidades, a procura por soluções judiciais de curto prazo acaba sendo uma alternativa viável para manter a subsistência e a dignidade de todos aqueles carentes de moradia, mesmo que provisoriamente.

\section{A IMPORTÂNCIA DA POSSE E A NECESSIDADE DE SUA DEFESA JURÍDICA}

Defendendo a superioridade social e econômica da posse sobre a propriedade, Valcir Gassen (apud MUNIZ, 2015, p. 1) afirma que "a posse da terra nasce das relações concretas entre os homens, sendo que, na trajetória da propriedade, esta sempre foi o mais importante meio de produção da riqueza". Essa superioridade ainda é salientada por Albuquerque (2002, p. 194):

A posse, em nossa dimensão territorial, é forma de aproveitamento econômico do solo e forma de produção de riqueza para o possuidor e para toda a sociedade. A posse é forma de ocupação primária, corresponde ao fim último de liberdade e de dignidade da pessoa humana, na medida em que possa estar ligada aos direitos de moradia, possa implementar a erradicação da pobreza e torne efetiva a igualdade entre todos.

Mas essas não são as únicas funções sociais da posse. Quando decorre da ocupação por parte de uma coletividade carente de moradia, a posse assume visível conotação política, já que denuncia tanto as insuficiências de políticas públicas habitacionais aptas à resolução do problema, quanto a existência de inúmeros imóveis sem qualquer função social. Deve-se salientar que as terras rurais ou urbanas não podem ser reproduzidas ou ampliadas, diferentemente de outros 
bens. Deste modo, usar os territórios de forma efetiva, eliminando os vazios especulativos, confere mais riqueza e desenvolvimento social a um país.

Além da importância marcante na área pública, a proteção da posse também é essencial para a harmonização das relações privadas. Quando se instaura um conflito no qual dois ou mais sujeitos se dizem proprietários de um mesmo bem, opta-se por manter o referido objeto do conflito sob os cuidados do atual possuidor, até que, em um segundo momento, seja verificada a titularidade do imóvel. Essa regra decorre do princípio da conservação do fático, nascido no direito romano e difundido por todo o mundo (RODRIGUES, 2014, p. 1). A razão de existência da aludida regra é desenvolvida a partir de uma conclusão lógica: se sempre que fosse expulso do seu imóvel o proprietário tivesse que provar sua condição sobre o bem, a prestação jurisdicional tardaria a resolver o conflito social (MUNIZ, 2015, p. 1). Provar ser o possuidor até a data do conflito é algo mais simples, algo que dará ensejo a uma decisão jurisdicional mais célere.

O objetivo de uma ocupação e da defesa da posse subsequente quase nunca é o de adquirir a propriedade do imóvel em questão. O proprietário do bem imóvel ingressará, posteriormente, com uma ação reivindicatória (em regra), que tem por característica o fato de ser mais lenta, já que é baseada na comprovação de titularidade sobre o bem e tem o andamento processual ordinário, assim como a grande maioria das milhões de ações que se enfileiram no Judiciário. Mas, até isso ocorrer, a garantia de que as ações possessórias não resultarão na remoção imediata dos ocupantes é um importante ganho para a mobilização social em torno da efetivação do direito à moradia.

Ao serem mantidos na posse do imóvel até que a propriedade seja avaliada pelo Judiciário, os ocupantes ganharão semanas ou meses a mais nos imóveis, resolvendo temporariamente a questão da falta de moradia. Uma ocupação prolongada acaba por revelar ainda mais a ausência de políticas públicas habitacionais capazes de dar aos habitantes das cidades o bem mais básico que qualquer ser humano deseja possuir: uma casa. Acrescenta-se ainda que a permanência dos possuidores serve de denúncia contra o proprietário que se omite de destinar função social ao seu imóvel. O poder público, com isso, se sente pressionado em aplicar as sanções cabíveis.

Nas palavras de Marcus Dantas (2013, p. 482):

Como se indicou, nas ocupações normalmente realizadas o objetivo não é "passar a ser o proprietário do bem", até mesmo porque o juiz não pode, pura e simplesmente, desapropriar um imóvel e passá-lo para o nome dos ocupantes. Em verdade, a atuação dos movimentos sociais [...] têm o objetivo de chamar a atenção das autoridades públicas para a existência de 
uma dúvida acerca do cumprimento da função social por parte do proprietário do bem ocupado.

Independente do forte embasamento jurídico e social que existe na ocupação urbana praticada por movimentos sociais, na maioria dos conflitos fundiários coletivos a defesa possessória não funciona devidamente. E aqui reside uma questão arraigada na cultura brasileira, perpetuada pela mídia e confirmada pelas decisões dos magistrados: a criminalização dos movimentos de ocupação, que se tornam "caso de polícia", situações que devem ser extirpadas das cidades em nome da paz social e da defesa da propriedade privada.

Resta ao próximo tópico a tarefa de avaliar se as alterações trazidas pelo novo CPC serão capazes de reverter essa lógica, possibilitando que as ocupações coletivas não sejam consideradas menos legítimas do que a manutenção de propriedades imóveis carentes de função social.

\section{CONTRAPONTOS ENTRE O CPC DE 1973 E O CPC DE 2016}

\section{Contexto social e político}

O CPC de 1973 foi outorgado durante um regime de exceção, iniciado no Brasil com o golpe militar de 1964. Na época, as demandas sociais eram tidas como opostas à ordem e à segurança nacional, e as ocupações coletivas juridicamente tiveram o mesmo tratamento simplório dado aos conflitos individuais (VIANA, 2014, p. 67). Deste modo, as demandas diversas contidas nos aludidos conflitos nunca teriam espaço adequado para ser discutidas ao longo do processo judicial. É claro que a CF/88 renovou toda a ordem jurídica do país, a ponto de muitos institutos jurídicos passarem a ser reinterpretados com o fim de se alinharem ao sistema. Infelizmente, isso não ocorreu, em termos práticos, com as ações possessórias.

Apesar de orientações como as do Conselho Nacional de Justiça (CNJ) para que os magistrados se pautem por princípios constitucionais atinentes ao direito à moradia e à função social da propriedade (DANTAS, 2013, p. 466), durante o julgamento das ações possessórias, as regras processuais civis ainda são aplicadas ou mal aplicadas de acordo com o que for mais conveniente para os proprietários. Ao magistrado é conferida ampla possibilidade de realizar despejos de grupos de ocupantes sem considerar a complexidade de direitos fundamentais envolvidos no caso concreto. A defesa da propriedade costuma ser a única motivação para todas as suas decisões.

Nos últimos anos, essa limitação da lei processual para considerar as peculiaridades das ocupações coletivas foi questionada pelos movimentos sociais e instituições ligados à causa da 
Reforma Urbana. E o momento parecia propenso. Um novo CPC estava sendo elaborado, dessa vez através de um processo altamente democrático. O PL que deu vida ao novo Código sofreu mais de novecentas emendas parlamentares durante todo o processo legislativo. Mais de trezentas pessoas foram ouvidas em audiências públicas, inclusive os membros de todas as entidades de classe e associações que apresentaram sugestões (DIDIER JR., 2013, p. 1). Mas nem por isso podemos dizer que as demandas progressistas para a modificação nas regras das ações possessórias foram bem atendidas. Durante a elaboração do $\mathrm{PL}$, forças conservadoras se posicionaram contra as demandas progressistas, com base no argumento de que as alterações propostas estimulariam as invasões coletivas, o que agravaria, segundo eles, os conflitos urbanos (SILVA, 2015, p. 9). Independente da superficialidade do argumento apresentado, as principais alterações processuais pleiteadas pelo movimento reformista foram barradas, conforme será demonstrado a partir de agora.

\section{Ação de força nova e de força velha}

Um elemento central para as ações possessórias é a questão da força nova e força velha. A lei civil brasileira resolveu conferir uma proteção maior àquele que intenta ação possessória no prazo de ano e dia, contado da data da agressão. As ações iniciadas dentro desse prazo são chamadas de força nova, e geram a possibilidade de conferir uma liminar própria para os seus autores. Tal liminar foge da regra geral do sistema jurídico brasileiro, pois não exige os requisitos comuns das demais liminares, mas apenas o disposto no artigo 927 do CPC de 1973:

I. Demonstrar a posse anterior sobre a coisa;

II. A turbação ou o esbulho praticado pelo réu;

III. A data em que a posse foi violada;

IV. A preservação da posse, embora turbada em se tratando de ação de manutenção e a perda da posse em se tratando de ação de reintegração.

A liminar permite ao juiz instituir a remoção dos ocupantes imediatamente. Caso o prazo transcorra, a ação será de força velha, e a liminar própria a ser apresentada não será mais concedida. Isso não quer dizer que o autor não possa intentar uma liminar comum, mas o que dificulta a sua concessão é o requisito periculum in $\mathrm{mora}^{9}$, difícil de ser provado para alguém que permaneceu por mais de um ano sem procurar reaver a posse de seu bem.

\footnotetext{
${ }^{9}$ Expressão latina que significa "perigo na demora". Por exigência desse requisito, o autor da ação deve provar que, caso a proteção jurídica que ele demanda tarde a ocorrer, pode haver dano de difícil ou incerta reparação. Isso motivaria a concessão de uma medida liminar, que protegeria seus interesses jurídicos até que a ação seja julgada posteriormente.
} 
Houve tentativas de se eliminar essas regras no novo CPC, caso o bem imóvel em questão não cumprisse uma função social, ou pelo menos quando se tratasse de ocupações coletivas.

Durante a elaboração do Projeto de Lei que originou o novo CPC, o Deputado Padre João chegou a encaminhar uma emenda parlamentar que procurou acrescentar o cumprimento da função social da propriedade como requisito para a concessão da liminar possessória. Na justificativa para a sua emenda o aludido deputado redigiu:

O requisito do cumprimento da função social para a tutela possessória é consequência direta da Constituição, em seus seguintes dispositivos: artigo 5ㅇ, inciso XXIII, artigo 170, inciso III, artigo 182 § 2으, artigo 184, artigo 185, parágrafo único e artigo 186, regulamentados pelas Leis no 10.257/ 2001 e 8.629/1993. Para o Ministro do Superior Tribuna de Justiça Teori Albino Zavascki, a função social da propriedade diz com a utilização dos bens, e não com sua titularidade. Função social da propriedade realiza-se "mediante atos concretos, de parte de quem efetivamente tem a disponibilidade física dos bens, ou seja, do possuidor, [...] seja ele detentor ou não de título jurídico a justificar sua posse". Por isso a função social diz mais respeito ao fenômeno possessório do que ao direito de propriedade. Esta é a importante lição do jurista Luis Edson Fachin, para quem a "função social é mais evidente na posse e muito menos evidente na propriedade". Não existe sentido, na ordem constitucional vigente, em se proteger posse que não cumpra sua função social (SIQUEIRA, 2011).

A supracitada emenda parlamentar acabou por ser rejeitada pela maioria dos legisladores, impedindo que a função social se tornasse um requisito para a concessão de liminares possessórias. Assim, indivíduos que abusam do seu direito de propriedade, não conferindo função social aos seus bens imóveis, continuam protegidos pela norma civil.

\section{Diferenciação entre posse individual e coletiva e a liminar própria das ações possessórias}

Enquanto o Código de 1973 não faz qualquer distinção processual nas ações possessórias individuais ou coletivas, o novo CPC apresenta uma tímida diferença processual entre eles. Nas ações que recaírem sobre a posse coletiva, haverá a necessidade da realização de audiência de mediação para que seja concedida medida liminar. Como veremos a seguir, essa alteração será menos utilizada na prática do que se pensa. No momento, cabe elucidar que o novo CPC trata a posse coletiva com praticamente o mesmo cuidado que trata a individual, apesar de serem manifestações totalmente diferentes do ponto de vista social e político. 


\section{A citação}

A lei processual civil atual permite que a citação em casos de ocupação coletiva seja feita por edital, ou seja, através de veículos de comunicação oficial ou não que, espera-se, chegará ao conhecimento dos réus. A ação, com base nisso, é proposta contra todos indistintamente, sem que se identifique cada um dos sujeitos envolvidos. Por ser uma citação ficta ou presumida, o processo seguirá mesmo que a coletividade de ocupantes não manifeste defesa.

A regra é descrita por processualista Marcus V. Gonçalves (2011, p. 784):

Não sendo possível a citação pessoal, seja porque o local tornou-se inacessível, seja porque não é possível identificar os invasores, o juiz autorizará que seja feita por edital, na forma do art. 231, I e II, do CPC.

Nota-se, por parte dos aplicadores do Direito, uma interpretação legal excludente, que transforma ocupantes em invasores perigosos que devem ser mantidos à distância, mesmo durante um processo judicial. É visível que o poder público, por meio de suas instituições, agrava a cada dia o quadro de segregação urbana. Além de destruir, muitas vezes, os modos de subsistência dos grupos sociais mais vulneráveis, estimula a separação de culturas dentro de uma mesma cidade, delimitando que algumas "classes perigosas" (DABROWSKI, 2003, p. 175) devem ter acesso restrito a devido processo legal, em nome da segurança dos agentes do Estado e do proprietário autor da ação.

As condições sociais dos ocupantes de imóveis urbanos muitas vezes impedem que eles tenham acesso aos meios de comunicação utilizados para propagar o edital, sendo que na maioria das vezes ela é veiculada em publicações oficiais do Judiciário, impressas ou virtuais. O resultado evidente disso é a remoção de pessoas que não tiveram a oportunidade de apresentar defesa. Para evitar esse notório atentado à legitima defesa e ao contraditório, o novo CPC dispõe, em seu artigo $554, \S 1$ 1ํ, que, “[...] no caso de ação possessória em que figure no polo passivo grande número de pessoas, serão feitas a citação pessoal dos ocupantes que forem encontrados no local e a citação por edital dos demais". Para isso, o oficial de justiça deverá procurar os ocupantes no local um por vez, citando-os individualmente. Apenas os que não forem encontrados após a diligência deverão ser citados por edital.

Para ampliar ainda mais a existência da demanda, o parágrafo terceiro do mesmo artigo 554 ainda dispõe que "[...] o juiz deverá determinar que se dê ampla publicidade da existência da ação prevista no $\S 1^{\circ}[\ldots]$, podendo, para tanto, valer-se de anúncios em jornal ou rádio locais, da publicação de cartazes na região do conflito e de outros meios". Dois são os efeitos imediatos 
desse dispositivo: primeiramente, aumentará a segurança dos ocupantes conhecerem a existência da ação possessória, e, em segundo lugar, permitirá que toda a sociedade tenha conhecimento do conflito possessório. Assim, tanto as omissões do Estado em prover moradia popular quanto a existência de terrenos urbanos carentes de função social serão levados a público.

Para que a defesa dos direitos da coletividade seja ainda mais efetivada, de forma simultânea à citação dos ocupantes ocorrerá a intimação do Ministério Público e da Defensoria Pública (em casos de hipossuficiência econômica). Espera-se que a participação desses órgãos em todas as ações possessórias coletivas reduza o número de violações ao direito da ampla defesa e do contraditório, além do respeito à dignidade dos ocupantes durante todo o processo judicial.

\section{A função social da propriedade como requisito de concessão da liminar}

Parte da doutrina aponta que, apesar da função social da propriedade não estar dentre os requisitos para concessão de liminar especificados no artigo 927 do CPC de 1973, uma simples análise sistemática do ordenamento jurídico poderia colocá-lo como tal. Isso decorre do fato de o sujeito que alega que sua posse foi violada injustamente deve provar que está exercendo essa posse dentro dos limites da legalidade, ou seja, deve demonstrar que a sua posse é justa. É esse o fundamento maior da ação possessória: coloca que a posse injusta deve deixar de existir, abrindo caminho para o exercício de uma posse justa. Então, se a função social é descumprida, a posse é injusta e, por isso, não merece proteção jurídica.

No âmbito das ações possessórias, a função social é tão importante, que muitos juízes costumam motivar as remoções com base no fato de o proprietário cumprir alguma função social. Analisando julgados do Paraná, Marcus E. Dantas (2013, p. 475) chegou à conclusão que os magistrados costumam colocar o cumprimento da função social como "[...] mecanismo de qualificação da posse quando tal verificação é benéfica para o autor da ação". O oposto acontece quando esse fato irá prejudicar o proprietário que ingressou com a ação, oportunidade em que os magistrados frisam que a função social da propriedade não é elemento a ser tratado durante a ação possessória, muito menos como fundamento para concessão de liminar.

O visível desequilíbrio entre as diferentes partes que compõem as ações possessórias preocupam os setores mais progressistas da sociedade há tempos. Isso motivou que parte das demandas levadas ao Congresso Nacional durante a elaboração do novo CPC fosse justamente relativas à inclusão da função social da propriedade como requisito para concessão de liminar. A análise dessa questão não poderia depender apenas do juízo de valor dos magistrados, mas, pelo 
contrário, deveria se tornar um arcabouço de regras das quais os juízes não poderiam deixar de seguir.

E essa talvez tenha sido a maior derrota da Reforma Urbana durante a confecção do novo Código: a ausência da função social da propriedade como requisito expresso.

\section{A audiência de mediação}

A concessão de liminar costuma ser um ato judicial que independe de uma análise mais profunda sobre o caso e de ouvir a versão da parte contrária. É uma medida excepcional no sistema jurídico, e é fornecida para casos em que o autor da ação possa apresentar elementos probatórios que permitam ao magistrado ter uma compreensão com relativa precisão, mesmo estando "à distância" do fato social que gerou o conflito jurídico. Há situações, por sua vez, em que o juiz, não conformado apenas com as alegações do autor da ação, pode entender necessária a avaliação mais profunda dos fatos. Duas medidas podem ser adotadas: (a) a inspeção judicial, pela qual o magistrado irá ao local gerador do conflito para se certificar da existência das circunstâncias que motivem a liminar; ou (b) audiência de justificação prévia, na qual o autor e o seu advogado serão convocados para fornecer mais esclarecimentos, podendo estar presente também o próprio, salvo se o conhecimento deste puder tornar a medida ineficaz.

Atente-se para o fato de que é o juiz que determinará, conforme o seu entendimento, se esses procedimentos serão ou não necessários. Esse é o motivo para na prática serem utilizados muito raramente, principalmente nos conflitos possessórios coletivos. Para reverter essa situação pela qual decisões são emitidas pelo Judiciário sem que haja uma análise mais fiel da realidade social, os movimentos sociais e instituições ligadas à causa da Reforma Urbana defenderam mudanças processuais que tornem a audiência de justificação prévia uma etapa obrigatória para a concessão das liminares, quando essas recaírem sobre uma ocupação coletiva. Durante os debates sobre o novo CPC, essa audiência foi aperfeiçoada até o ponto de criarem o instituto da audiência de mediação.

Segundo o artigo 565 do novo CPC, nas ações possessórias de força velha, a liminar só poderá ser concedida após audiência de mediação a ser realizada no prazo de 30 dias. O Ministério Público e a Defensoria Pública serão intimados a comparecer, assim como órgãos responsáveis pela política agrária ou urbana dos três níveis de governo. Por ser uma audiência de mediação, os réus terão espaço obrigatório nelas. Assim, o juiz deverá ouvir as suas versões e conhecer as suas perspectivas antes de conceder a liminar. 
A audiência de mediação seria uma grande inovação do novo CPC caso não fosse restrita às ações possessórias de força velha. Possuidores que ocupem imóveis por menos de um ano e dia não poderão se valer desse recurso tão importante para a construção política e social do direito à moradia.

\section{CONSIDERAÇÕES FINAIS}

A dinâmica com que o Judiciário encara as ações possessórias necessita de mudanças capazes de impedir que os juízes decidam sem observarem os valores contidos nos documentos internacionais de direitos humanos e na CF/88. Não resta dúvida que as remoções forçadas são uma ameaça à concretização de uma diversidade de direitos humanos fundamentais. Sabe-se que o acesso à moradia adequada é uma pré-condição para "[...] a realização de vários outros direitos humanos, incluindo o direito a trabalho, saúde, segurança social, voto, privacidade, dentre outros" (BRASIL, 2013, p. 69), e isso se explica pelo fato dos direitos humanos serem indivisíveis e interrelacionados, principalmente um direito tão essencial como o de ter um lugar onde habitar. 0 próprio direito à cidade, enquanto potencialidade para viver a cidade e participar do seu projeto futuro, parte do princípio que o cidadão deve primeiro se estabilizar em um local, para que depois possa encarar a dinamicidade urbana. Sem a estabilidade, não se vive o dinâmico.

Depois de lutar pela elaboração normativa que enriquecesse o conteúdo do direito à moradia, os movimentos sociais e instituições ligados à causa da Reforma Urbana foram assertivos em direcionar seus esforços para modificar as regras processuais que transformam esse direito em decisões judiciais favoráveis às populações segregadas sócio e espacialmente. O problema é que o recente envolvimento com as modificações no CPC não geraram tantos frutos, como pode ser verificado nos tópicos anteriores. Dificilmente as novas regras irão produzir melhorias significativas na concretização do direito à moradia e no respeito a outros direitos humanos.

Independentemente das modificações do novo CPC serem tímidas, elas precisam ser conhecidas e aproveitadas ao máximo. Além disso, as suas limitações precisam ser bem delimitadas, para que se tornem fundamentos de futuros debates na arena política. Reconhecendo essas necessidades, o presente estudo apontará, de forma objetiva, para alguns pontos que merecem atenção de todos aqueles que se debruçam sobre a temática do direito à cidade e do direito à moradia. Esses mesmos pontos se tornarão experiências interessantes para serem apresentadas, inter-relacionadas e (re) assimiladas pelo Brasil no contexto internacional, sobretudo na conferência da Habitat 3, da ONU. É o momento de mencioná-los: 
1. A posse não é uma ameaça ao direito de propriedade. As ações possessórias não podem ensejar a assimilação da propriedade por parte do possuidor. Elas apenas o mantém na posse até que a titularidade do imóvel seja avaliada em ação posterior, mantendo a paz social até lá. É, por isso, um instrumento de estabilização social fundamental para a sobrevivência do próprio instituto da propriedade privada. A opinião pública, baseada em interpretações midiáticas e excludentes, acaba colocando as remoções como alternativa necessária para que o proprietário retome o seu imóvel, o que não passa de uma grande falácia. Nesses casos, a única forma que um sujeito pode perder a sua condição de proprietário perante o bem é a seguinte: a ocupação coletiva pode levantar questionamentos do poder público com relação à existência de função social em determinado imóvel urbano, o que pode ensejar medidas como a expropriação. Salienta-se que isso não decorre da ocupação em si, mas do cumprimento das normas constitucionais que não permite que imóveis urbanos permaneçam com quem não os dê função social (MARÉS, 2003, p. 117).

2. Em análise sistemática do atual ordenamento jurídico processual, já existe a possibilidade de a função social da propriedade se inserir no rol de requisitos para a concessão de liminar. O proprietário que não dá destinação social ao seu imóvel urbano, descumprido preceitos constitucionais, tem apenas a posse injusta sobre o mesmo e, por isso, não merece a proteção jurídica. O presente estudo abordou a essencialidade que a função social da propriedade tem para a efetivação do direito à moradia.

3. A questão da posse de má-fé por parte dos ocupantes de imóveis urbanos que não cumprem função social deve ser enfrentada com os mesmos argumentos. A posse em ocupações de movimentos sociais é tida como injusta pela maioria dos aplicadores do Direito. Mas o fato do proprietário também não ter a posse justa acaba por impedindo que a permanência dos ocupantes no imóvel litigioso seja interrompida por ação possessória.

4. A citação de todos os ocupantes se tornou elemento obrigatório na ação possessória. Caso seja descumprida, a própria decisão judicial poderá ser derrubada posteriormente, por meio de ação rescisória. Talvez seja um mecanismo capaz de reverter mandados de despejo decididos com cerceamento de defesa.

5. As liminares precisam ser medidas judicias excepcionais nos casos de conflitos fundiários coletivos, aliás, elas têm a característica de verdadeiras tutelas antecipadas, já que "[...] a retirada imediata dos ocupantes esvazia completamente o fato social criado com a 
ocupação, o que dificulta a reversão do resultado posteriormente reconhecido como injusto" (DANTAS, 2013, p. 480).

6. A audiência de mediação será um instituto pouco verificado na prática, já que fica restrita às ações de força velha. Mesmo assim, as instituições e os movimentos sociais ligados à causa da Reforma Urbana devem se aperfeiçoar no sentido de aproveitar ao máximo as oportunidades que possam surgir com a audiência. Um cuidado, porém, deverá ser tomado: a mediação a ser aplicada nessas audiências não deve ser feita com técnicas convencionais de resolução de conflito, úteis nos litígios privados, mas prejudiciais em situações que envolvem grande número de pessoas vulneráveis socialmente. A mediação não pode encarar os dois lados como iguais, pois direitos dos mais fundamentais estão sendo confrontados com privilégios.

7. A evolução dos aspectos processuais que possibilitam a resolução dos conflitos fundiários coletivos também precisam compreender outros institutos jurídicos além da posse. Instrumentos como a usucapião urbana e a concessão real do direito de uso, por exemplo, poderiam se tornar mais presentes no cotidiano das cidades brasileiras caso fossem regidos por regras processuais que considerassem os direitos fundamentais envolvidos nos litígios jurídicos advindos, sobretudo, de ocupações coletivas.

8. Independente dos avanços normativos ocorridos nas últimas décadas, a cultura do Judiciário precisa ser modificada, no sentido de formar juízes mais aptos a resolver os conflitos fundiários considerando os direitos fundamentais envolvidos, e consolidando os dispositivos constitucionais atinente à efetivação do direito à cidade. A própria estrutura do judiciário deve abrir espaço para a criação de varas próprias para o julgamento de conflitos fundiários urbanos, que agreguem funcionários públicos capazes de captarem as nuances que emanam do referido conflito.

As reais consequências que o novo CPC trará aos conflitos fundiários urbanos ainda são desconhecidas. Deverão ser analisadas com o passar do tempo, para que depois possam ser debatidas entre os diversos segmentos da sociedade. Sabe-se que a mera modificação legislativa muitas vezes não é capaz efetivar direitos, necessitando de um grande esforço social no sentido de controlar o processo de aplicação das normas jurídicas. E uma real mudança relativa à efetivação de direitos humanos fundamentais não está dissociada do próprio meio como o Direito é apresentado à sociedade. 
No Brasil, o sistema jurídico ainda é tido mais como uma estrutura de normas a ser imposta à sociedade, e não como um instrumento a serviço dessa sociedade. Pensa-se no direito enquanto formalidade, e não enquanto função. Ensina-se "o que é direito", mas pouco sobre "para que serve o direito" (BOBBIO, 2007, p. 51). Essa mudança de perspectiva, chamada de Teoria Funcional do Direito, é proposta por Norberto Bobbio, e aponta para outro foco na relação entre a lei e os seres que são regidos por elas.

Uma nova teoria sobre o Direito também traria entendimentos mais relevantes sobre a proteção jurídica da propriedade. Difundir "para que serve o direito de propriedade" seria um grande passo para que a função social da cidade pudesse ser melhor desenvolvida no ordenamento jurídico brasileiro. E, seguindo o ponto de vista de Jacques Távora Alfonsin (2006, p. 175), essa função da propriedade deve receber status de "social" somente se servir como vetor de desenvolvimento dos direitos sociais, dentre os quais o direito à moradia é um dos mais fundamentais.

\section{REFERÊNCIAS}

ALBUQUERQUE, Ana Rita Vieira. Da função social da posse e sua consequência frente à situação proprietária. Rio de Janeiro: Lumen Juris, 2002.

ALFONSIN, Betânia de M. Políticas de regularização fundiária: justificação, impactos e sustentabilidade. In: FERNANDES, Edésio (Org.). Direito urbanístico e política urbana no Brasil. Belo Horizonte: Del Rey, 2000.

ALFONSIN, Jacques T. Do "diga que não estou" à relação entre pobreza e função social da terra no Brasil. In: FERNANDES, Edésio (Org.). Direitos urbanísticos: estudos brasileiros e internacionais. Belo Horizonte: Del Rey, 2006.

AMADO, Aécio. Informações sobre o censo 2010. Disponível em: <http://memoria.ebc.com.br/agenciabrasil/>. Acesso em: 27 jul. 2015.

BOBBIO, Norberto. Da estrutura à função: novos estudos de teoria do Direito. Barueri: Manole, 2007.

BOULOS, Guilherme. Por que ocupamos? - Uma introdução à luta dos sem teto. São Paulo: Scortecci, 2012.

BRASIL. Ministério das Cidades. Regularização Fundiária Urbana: como aplicar a Lei Federal $\mathrm{n}^{\circ}$ 11.977/2009. Brasília: Ministério das Cidades, Secretaria Nacional de Habitação e Secretaria Nacional de Programas Urbanos, 2010. 
Secretaria de Direitos Humanos da Presidência da República. Direito à moradia adequada. Brasília: Secretaria Nacional de Promoção e Defesa dos Direitos Humanos, 2013.

Ministério da Justiça. Secretaria de Reforma do Judiciário. Atuação da Justiça nos Conflitos Fundiários Urbanos. Brasília: Ministério da Justiça, 2013.

CAMPOS, Núbia. A efetividade do direito à moradia no judiciário brasileiro: uma análise comparativa da jurisprudência. Disponível em: <http://www.sbdp.org.br/arquivos/monografia/175_Nubia\%20Carla\%20Campos.pdf>. Acesso em: 10 set. 2015.

CASTRO, Sônia R. de. Formas diferentes de se pensar e de se reconstruir o direito de propriedade e os direitos de posse nos "países novos". In: FERNANDES, Edésio (Org.). Direito urbanístico e política urbana no Brasil. Belo Horizonte: Del Rey, 2000.

DABROWSKI, Delphine S. As raízes ideológicas da segregação no Brasil: o exemplo de salvador. In: ESTEVES JÚNIOR, Milton; URIARTE, Urpi Montoya (Org.). Panoramas urbanos: reflexões sobre a cidade. Salvador: EDUFBA, 2003.

DANTAS, Marcus E. Função social na tutela possessória em conflitos fundiários. Revista DIREITO GV, São Paulo, jul. /dez. 2013.

DIDIER JR., Fredie. Um Código de Processo Civil democrático. 14/04/2013. Disponível em: <http://www.frediedidier.com.br/editorial/editorial-169/>. Acesso em: 28 jul. 2015.

GONÇALVES, Marcus V. R. Direito processual civil. 2. ed. São Paulo: Saraiva, 2012.

MARÉS, Carlos F. A função social da terra. Porto Alegre: S. A. Fabris Editor, 2003.

MATTOS, Liana P. Limitações Urbanísticas à Propriedade. In: FERNANDES, Edésio (Org.). Direito urbanístico e política urbana no Brasil. Belo Horizonte: Del Rey, 2000.

MUNIZ, C. Da função social da posse. Disponível em: $<$ http://edeziomuniz.jusbrasil.com.br/artigos/111827004/da-funcao-social-da-posse >. Acesso em: 28 jul. 2015.

ORGANIZAÇÃO DAS NAÇÕES UNIDAS (ONU). Pacto Internacional sobre os Direitos Econômicos, Sociais e Culturais. Disponível em: <http://www.gddc.pt/direitos-humanos/textos-internacionaisdh/tidhuniversais/cidh-dudh-psocial.html>. Acesso em: 27 set. 2014.

Declaração Universal dos Direitos Humanos. Disponível em <http://www.dudh.org.br/>. Acesso em: 13 ago. 2015.

RODRIGUES, Ricardo Wey. A posse - definição, características e efeitos. 31/01/2014. Disponível em: $\quad<$ http://www.conteudojuridico.com.br/artigo,a-posse-definicao-caracteristicas-eefeitos,46850.html >. Acesso em: 25 abr. 2015.

SILVA, Sílvio M. O novo CPC e a mediação como meio de solução de controvérsias. Disponível em: <http://www5.tjba.jus.br/O_Novo_CPC.pdf>. Acesso em: 14 jul. 2015. 
SIQUEIRA, João C. Emenda ao Projeto de Lei no 8.046/2010. Disponível em: $<$ http://www2.camara.leg.br/proposicoesWeb/prop_mostrarintegra?codteor=938648\&filename=E MC+322/2011+PL602505+\%3D\%3E+PL+8046/2010>. Acesso em: 20 abr. 2015.

VIANA, Cíntia P. Mediação como política pública de estado em conflitos fundiários urbanos no Brasil: reflexões sobre a proposta do novo CPC. O Social em Questão, Rio de Janeiro: PUC-Rio, ano 18, n. 31, p. 57-72, 2014. Disponível em: <http:osocialemquestao.ser.pucrio.br/media/OSQ_31_3_Viana.pdf>. Acesso em: 14 jul. 2015.

Trabalho enviado em 26 de setembro de 2015.

Aceito em 07 de novembro de 2015. 